ARTICLE

\title{
A sandwich-type cluster containing Ge@Pd 3 planar fragment flanked by aromatic nonagermanide caps
}

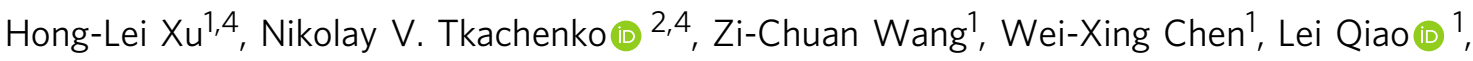 \\ Alvaro Muñoz-Castro ${ }^{3}$, Alexander I. Boldyrev (i) ${ }^{2 \otimes} \&$ Zhong-Ming Sun (1) ${ }^{1 凶}$
}

Sandwich-type clusters with the planar fragment containing a heterometallic sheet have remained elusive. In this work, we introduce the $[\mathrm{K}(2,2,2-\mathrm{crypt})]_{4}\left\{\left(\mathrm{Ge}_{9}\right)_{2}\left[\eta^{6}-\mathrm{Ge}\left(\mathrm{PdPPh}_{3}\right)_{3}\right]\right\}$ complex that contains a heterometallic sandwich fragment. The title compound is structurally characterized by means of single-crystal X-ray diffraction, which reveals the presence of an unusual heteroatomic metal planar fragment $\mathrm{Ge} @ \mathrm{Pd}_{3}$. The planar fragment contains a rare formal zerovalent germanium core and a peculiar bonding mode of $s p^{2}-\mathrm{Ge} @\left(\mathrm{PdPPh}_{3}\right)_{3}$ trigonal planar structure, whereas the nonagermanide fragments act as capping ligands. The chemical bonding pattern of the planar fragment consists of three 2c-2e Pd-Ge $\sigma$-bonds attaching Pd atoms to the core Ge atom, while the binding between the planar fragment and the aromatic $\mathrm{Ge}_{9}$ ligands is provided by six 2c-2e Pd-Ge $\sigma$-bonds and two delocalized 4c-2e $\sigma$-bonds. The synthesized cluster represents a rare example of a sandwich compound with the heteroatomic metal planar fragment and inorganic aromatic capping ligands.

\footnotetext{
${ }^{1}$ Tianjin Key Lab for Rare Earth Materials and Applications, State Key Laboratory of Elemento-Organic Chemistry, School of Materials Science and Engineering, Nankai University, 300350 Tianjin, China. ${ }^{2}$ Department of Chemistry and Biochemistry, Utah State University, O300 Old Main Hill, Logan, UT 84322-0300, USA. ${ }^{3}$ Grupo de Química Inorgánicay Materiales Moleculares, Facultad de Ingenieria, Universidad Autonoma de Chile, El Llano Subercaseaux, 2801 Santiago, Chile. ${ }^{4}$ These authors contributed equally: Hong-Lei Xu, Nikolay V. Tkachenko. ${ }^{凶}$ email: a.i.boldyrev@usu.edu; sunlab@nankai.edu.cn
} 
S ince the first sandwich complex $\left(\mathrm{C}_{5} \mathrm{H}_{5}\right)_{2} \mathrm{Fe}$, which was discovered in 1951, ferrocene and its derivatives have been the subject of intense research and many applications have been developed in chemical synthesis, catalysis, and materials science $^{1-4}$. Inspired by this discovery, various organic cyclic $\pi$ ligands were developed matching their orbitals symmetry with a metal center for generation of a vast array of metallocenes ${ }^{5-8}$. In 2002, an inorganic ligand cyclo- $\mathrm{P}_{5}{ }^{-}$was applied for the complex $\left[\left(\mathrm{P}_{5}\right)_{2} \mathrm{Ti}\right]^{2-}$ to stabilize a $\mathrm{Ti}(0)$ center (Fig. $\left.1 \mathrm{a}\right)^{9}$. This compound represents the first all-inorganic sandwich complex and promoted the growth of an interdisciplinary research area. Besides the development of ligands, the types of interlayer have also been extended to the polyatomic metal core, and the representative examples are the $\left[\mathrm{Pd}_{3} \mathrm{Tr}_{2} \mathrm{Cl}_{3}\right]^{-}\left(\mathrm{Tr}=\mathrm{C}_{7} \mathrm{H}_{7}\right)$ and other analogous sandwich compounds containing different $\mathrm{Pd}$ interlayers ${ }^{10-13}$. Moreover, those complexes provide possibilities to broaden the applications of metallocenes in catalysis due to the catalytically active palladium. In addition, such metal monolayer compounds are suitable models for the construction of some bulky systems, for instance, metal-graphite-based materials ${ }^{14}$. An example of a sandwich complex that combines both a polyatomic interlayer and inorganic ligands is the all-metal cluster $\left[\mathrm{Sb}_{3} \mathrm{Au}_{3} \mathrm{Sb}_{3}\right]^{3-}$, which furtherly broke prior limitation on the ligands and opened up more opportunities to build new types of sandwich compounds (Fig. 1a) ${ }^{15}$. Additionally, a sandwich-type cluster $\left[\mathrm{Au}_{3} \mathrm{Ge}_{18}\right]^{5-}$ where a $\mathrm{Au}_{3}$ ring was flanked by two different $\mathrm{Ge}_{9}$ clusters further promoted the progress of ligands for sandwich compounds (Fig. 1b) ${ }^{16}$. The analogous structure was also presented in both 18-vertex hypho-deltahedron clusters $\left[\mathrm{Ge}_{18} \mathrm{P}\right.$ $\left.\mathrm{d}_{3}\left(\mathrm{E}^{\mathrm{i}} \mathrm{Pr}_{3}\right)_{6}\right]^{2-}(\mathrm{E}=\mathrm{Si}, \mathrm{Sn})$ with a $\mathrm{Pd}_{3}$-triangle inside, despite the broken $\mathrm{Ge}_{9}$ units (Fig. 1b) ${ }^{17,18}$. In this work, we report the synthesis and characterization of a sandwich-type anionic species $\left\{\left(\mathrm{Ge}_{9}\right)_{2}\left[\eta^{6}-\mathrm{Ge}\left(\mathrm{PdPPh}_{3}\right)_{3}\right]\right\}^{4-}$ in which a trigonal planar fragment $\mathrm{Ge} @ \mathrm{Pd}_{3}$ is jammed between two aromatic $\mathrm{Ge}_{9}$ units. It is not only an extension of sandwich complex type to heteroatomic metal interlayer species, but also exhibiting an unusual stabilization mechanism of zerovalent main group elements.

\section{Results}

Synthesis and characterization. The compound $[\mathrm{K}(2,2,2-$ crypt $]_{4}\left\{\left(\mathrm{Ge}_{9}\right)_{2}\left[\eta^{6}-\mathrm{Ge}\left(\mathrm{PdPPh}_{3}\right)_{3}\right]\right\}$ was obtained by the reaction of an ethylenediamine (en) solution of $\mathrm{K}_{4} \mathrm{Ge}_{9}$ with (Triphenylphosphoranylidene)acetonitrile $\left(\mathrm{NC}-\mathrm{CPPh}_{3}\right)$ and $\mathrm{Pd}\left(\mathrm{PPh}_{3}\right)_{4}$ in the presence of 2,2,2-crypt $(4,7,13,16,21,24$-hexaoxa-1,10-diazabicyclo [8.8.8] hexacosane). These phosphines, such as $\mathrm{PPh}_{3}$, not only can act as useful ligands for organometallic compounds, but also are potential to be used as a mild oxidizing agent in $\mathrm{Ge}_{9}$ cluster chemistry based on the study of Sevov ${ }^{19,20}$. Here, the $\mathrm{NC}-\mathrm{CPPh}_{3}$ was used, similar to $\mathrm{PPh}_{3}$, to change the reactivity of parent $\mathrm{Ge}_{9}$ cluster by decrease the negative oxidation state. The black needlelike crystals were observed in the test tube after two weeks (17\% yield based on $\mathrm{K}_{4} \mathrm{Ge}_{9}$ ). The $\mathrm{X}$-ray diffraction analysis (XRD) reveals that the complex crystallizes in the monoclinic space group $P 2_{1} / n$ and the asymmetric unit contains two crystallographically distinct $\left\{\left(\mathrm{Ge}_{9}\right)_{2}\left[\eta^{6}-\mathrm{Ge}\left(\mathrm{PdPPh}_{3}\right)_{3}\right]\right\}^{4-}$ anions with eight $[\mathrm{K}(2,2,2 \text {-crypt })]^{+}$cations (Fig. 2 and Supplementary Fig. 2). The anion $\left\{\left(\mathrm{Ge}_{9}\right)_{2}\left[\eta^{6}-\mathrm{Ge}\left(\mathrm{PdPPh}_{3}\right)_{3}\right]\right\}^{4-}$ exhibited a specific sandwich structure in which heterometallic $\mathrm{Ge@}\left(\mathrm{PdPPh}_{3}\right)_{3}$ planar fragment located between the two $\mathrm{Ge}_{9}$ subunits with a nonlinear $\mu_{3}-\eta^{1}: \eta^{1}: \eta^{1}$-coordination mode (Fig. 2a).

Considering very similar structural characteristics for the two individual anionic clusters $\left\{\left(\mathrm{Ge}_{9}\right)_{2}\left[\eta^{6}-\mathrm{Ge}\left(\mathrm{PdPPh}_{3}\right)_{3}\right]\right\}^{4-}(1$ and 2 , see in the Supplementary Fig. 2 and Supplementary Data 1), the following discussion will mainly focus on cluster-1 and the significant differences will be appropriately pointed out. In the title cluster-1/2, two $\mathrm{Ge}_{9}$ subunits (A: Ge1-9 for 1, Ge21-29 for 2; B: Ge11-19 for 1, Ge31-39 for 2) possess almost identical shapes, which can be described as a quasi- $D_{3 h}$ symmetric tricapped trigonal prism (Fig. 2b). In the subunit $\mathrm{B}$, the opposite triangular surfaces of the prism are nearly parallel with a very small dihedral angle of 1.38 (1.26 for 2, degrees), while the A has more obvious deviation due to a larger angle value of 5.98 (5.44 for 2, degrees). Analysis of the structural distortions of each $\mathrm{Ge}_{9}$ subunit in comparison to an ideal $D_{3 \mathrm{~h}}$-tricapped trigonal prism (ttp) and $C_{4 \mathrm{v}}$-capped square antiprism (csa) was made by using the CShM $\operatorname{code}^{21,22}$. These results show a deviation of $0.549 \AA$ (root-meansquare, rms) and $0.480 \AA \mathrm{rms}$, for each subunit, in relation to a $D_{3 \mathrm{~h}}$-ttp structure, and a larger deviation in comparison to $C_{4 \mathrm{v}}$-csa (1.218 and $1.522 \AA \mathrm{rms}$ ). Thus, each subunit retains a closo- $D_{3 \mathrm{~h}}$ character, showing small distortions in comparison to an ideal ttp deltahedron.

In the $\mathrm{Ge}_{9}$ subunits of cluster-1, the lengths of the prisms (A: Ge1-Ge4, 2-5, 3-6: 2.808-3.060 A, the longest one 3-6; B: Ge11-Ge14, 12-15, 13-16: 2.866-2.930 $\AA$, the longest one 13-16) are elongated compared with those (2.71-2.73 $\AA$ ) in bare $\left[\mathrm{Ge}_{9}\right]^{2-}$ cluster with tricapped trigonal prismatic structure $^{23}$, and which are in good agreement with the corresponding values of similar $\mathrm{Ge}_{9}$ subunits in cluster-2 (A: Ge21-Ge24, 22-25, 23-26: 2.817-3.042 $\AA$, the longest one 22-25; $\mathrm{B}$ : Ge31-Ge34, 32-35, 33-36: 2.860-2.913 $\AA$, the longest one $32-35)$ ). Such elongation of prism lengths also exists in the reported $\left[\mathrm{Au}_{3} \mathrm{Ge}_{18}\right]^{5-}(2.879-3.027 \AA)^{16}$. This kind of prism lengths extension may be closely related to the interaction between the $\mathrm{Ge}_{9}$ subunits and the $\mathrm{Ge} @ \mathrm{Pd}_{3}$ moiety. In order to better describe the shapes of nine-atom Ge clusters, a related ratio $h / e$ where $\mathrm{h}-$ mean prism height and $\mathrm{e}-$ mean edge length is calculated for the distorted trigonal prism of $A(\mathrm{Ge} 1$, $\mathrm{Ge} 2, \mathrm{Ge} 3, \mathrm{Ge} 4, \mathrm{Ge} 5, \mathrm{Ge} 6)$ and $\mathrm{B}$ (Ge11, Ge12, Ge13, Ge14, Ge15, Ge16), which shows the distortions away from an idealized limit ${ }^{16,24}$. The values of $h / e$ in $\mathrm{A}$ and $\mathrm{B}$ are almost identical, $\sim 1.08$, fitting in with that (1.08 for two corresponding $\mathrm{Ge}_{9}$ subunits) in cluster-2, which is very close to- $\left[\mathrm{Ge}_{9}{ }^{2-}\right]-$ $(1.07)^{25}$ and $\left[\mathrm{Ge}=\mathrm{Ge}_{9}=\mathrm{Ge}_{9}\right]^{6-}(\sim 1.10)^{19}$, and lies in the range of those in $\left[\mathrm{Ge}_{9}\right]^{2-}(\sim 1.00)^{23},\left[\mathrm{Ge}_{9}-\mathrm{Ge}_{9}\right]^{6-}(1.12)^{26}$ and $\left[\mathrm{Au}_{3} \mathrm{Ge}_{18}\right]^{5-}(1.14)^{16}$. In addition, the six capping atoms (Ge7-9, Ge17-19) are not symmetrically located above the rectangular sides of the trigonal prism but are shifted in the direction of the planar fragment of binary $\mathrm{Ge} @ \mathrm{Pd}_{3}$ center. Such trend was also observed in the cluster-2, similar to the reported cluster $\left[\mathrm{Au}_{3} \mathrm{Ge}_{18}\right]^{5-16}$. The distances $(2.526-2.561 \AA)$ between these capping Ge-atoms (Ge7-9 and Ge17-19) and the Geatoms adjacent to the $\mathrm{Pd}$-atoms (Ge1-3 and Ge11-13) are significantly shorter compared with those of other $\mathrm{Ge}-\mathrm{Ge}$ bonds in the cap $(2.615-2.660 \AA)$ in the cluster-1. Whereas the Ge-Ge distances (2.718-2.764 $\AA$ ) within the two coordinated triangular faces (Ge1-3 and Ge11-13) are almost consistent with the corresponding triangular faces in the bare $\left[\mathrm{Ge}_{9}\right]^{2-}$ cluster $(2.73-2.759 \AA)^{23}$, the lengths in other triangular faces (Ge4-6 and Ge14-16) are remarkably shorter (2.593-2.670 A). Not surprisingly, the similar situation also occurs in the cluster-2.

In the peculiar planar fragment $\mathrm{Ge} @ \mathrm{Pd}_{3}$, the $\mathrm{Pd}-\mathrm{Ge}$ bond lengths (av. 2.416 $\AA$ for 1; $2.422 \AA$ for 2) are considerably shorter than those in other Pd-Ge bonds (av. $2.517 \AA$ for $1 ; 2.498 \AA$ for 2 ) between the $\mathrm{Ge} \mathrm{Pd}_{3}$ triangle and $\mathrm{Ge}_{9}$ fragments and even in other $\mathrm{Pd}-\mathrm{Ge}$ cluster anions, such as $\left[\mathrm{Ge}_{9} \mathrm{PdPPh}_{3}\right]^{3-}(2.54-2.64 \AA)^{27},\left[\mathrm{Ni}\left(\mathrm{Ge}_{9} \mathrm{PdPPh}_{3}\right)\right]^{2-}$ $(2.49-2.51 \AA)^{27},\left[\mathrm{Pd}_{2} @ \mathrm{Ge}_{18}\right]^{4-}(2.61-2.63 \AA)^{28}\left[\left(\mathrm{Me}_{3} \mathrm{Si}\right) \mathrm{Si}\right]_{3} \mathrm{Et}-$ $\mathrm{Ge}_{9} \mathrm{Pd}\left(\mathrm{PPh}_{3}\right)(2.43-2.73 \AA)^{29}$ and $\left[\mathrm{Ge}_{18} \mathrm{Pd}_{3}\left(\mathrm{E}^{\mathrm{i} P \mathrm{Pr}_{3}}\right)_{6}\right]^{2-}(\mathrm{E}=$ Si, Sn) (Si: 2.457-2.741 $\AA$; Sn: $2.447-2.728 \AA)^{17,18}$. In turn, the $\mathrm{Pd}-\mathrm{Ge}$ bond lengths in cluster-2 lie in a narrower range 
a

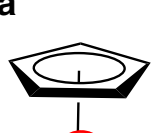

$\mathrm{Fe}$
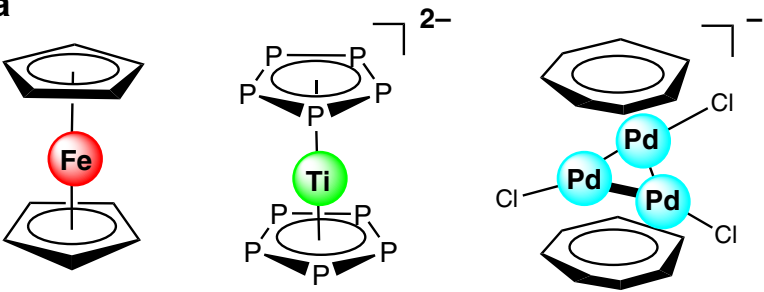

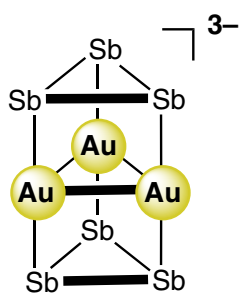

b

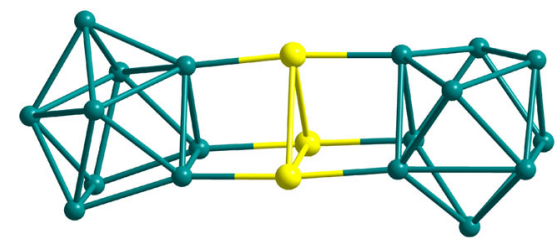

$\left[\mathrm{Au}_{3} \mathrm{Ge}_{18}\right]^{5-}$

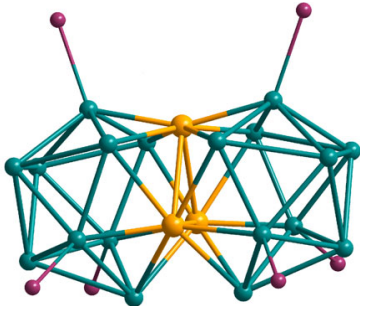

$\left[\mathrm{Ge}_{18} \mathrm{Pd}_{3}\left(\mathrm{Si}^{\mathrm{i}} \mathrm{Pr}_{3}\right)_{6}\right]^{2-}$

Fig. 1 Schematic representations and structures of selected examples of known sandwich complexes. a Schematic representations of selected sandwich complexes. b Structures of analogous $\mathrm{Ge}$-containing sandwich complexes. (Ge-atoms are green, $\mathrm{Au}$-atoms are yellow, $\mathrm{Pd}$-atoms are orange, and $\mathrm{Si}$-atoms are purple).

a

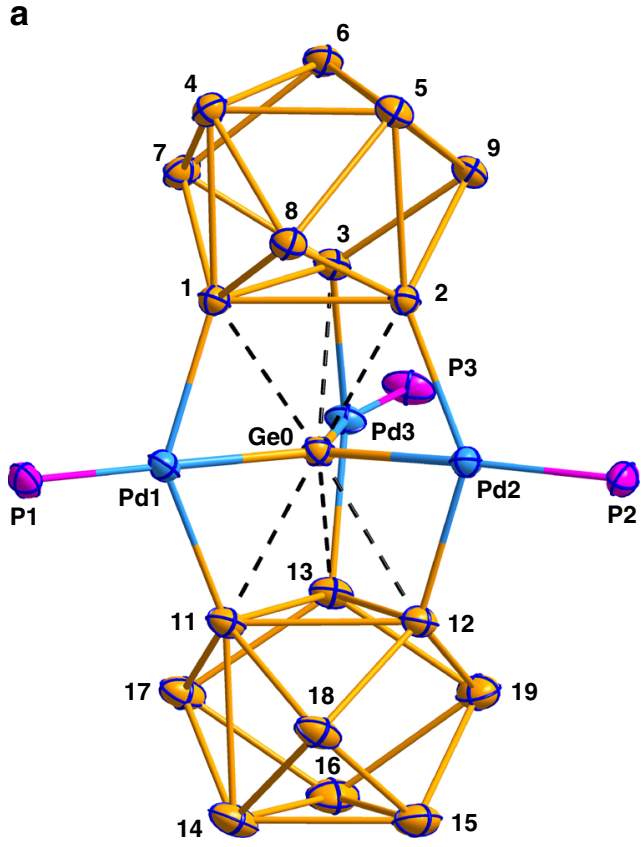

b
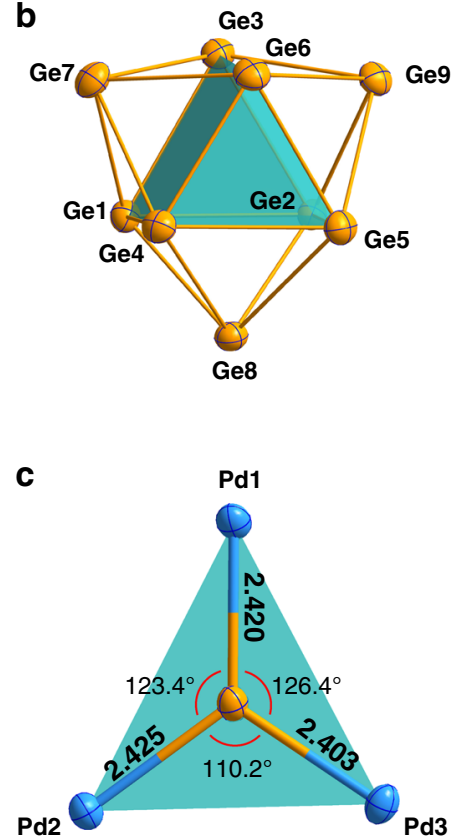

Fig. 2 Structures of the cluster-1 $\left\{\left(\mathrm{Ge}_{9}\right)_{2}\left[\eta^{6}-\mathrm{Ge}\left(\mathrm{PdPPh}_{\mathbf{3}}\right)_{3}\right]\right\}^{\mathbf{4}-}$ and its selected fragments. a The structure of the cluster-1, $(\mathrm{H}$ and $\mathrm{C}$ atoms are omitted for clarity, displacement ellipsoids with $35 \%$ probability). b The structure of $\mathrm{Ge}_{9}$ subunit. c The structure of planar $\mathrm{Ge@Pd_{3 }}$ subunit. Interatomic distances are given in $\AA$. Selected bond distances (angstroms) and angles (degrees): Ge1-Ge2: 2.744, Ge1-Ge3: 2.728, Ge2-Ge3: 2.718, Ge11-Ge12: 2.764, Ge12-Ge13: 2.751, Ge11-Ge13: 2.751, Ge4-Ge5: 2.670, Ge4-Ge6: 2.593, Ge5-Ge6: 2.619, Ge14-Ge15: 2.625, Ge14-Ge16: 2.612, Ge15-Ge16: 2.620, Ge2-Ge5: 2.808, Ge1-Ge4: 2.830, Ge3-Ge6: 3.061, Ge11-Ge14: 2.866, Ge12-Ge15: 2.893, Ge13-Ge16: 2.930 Pd1-Ge1: 2.475, Pd1-Ge11: 2.505, Pd3-Ge3: 2.533, Pd3-Ge13: 2.514, Pd2-Ge2: 2.482, Pd2-Ge12: 2.492. Ge1-Pd1-Ge11: 138.92, Ge1-Pd1-Ge0: 69.65, Ge11-Pd1-Ge0: 69.27, Ge2-Pd2-Ge12: 140.93, Ge2-Pd2-Ge0: 70.35, Ge12-Pd2-Ge0: 71.08, Ge3-Pd3-Ge13: 142.31, Ge3-Pd3-Ge0: 72.08, Ge13-Pd3-Ge0: 70.36.

(2.417-2.426 $\AA$ for $\mathrm{Ge@Pd}$; 2.486-2.525 $\AA$ for others) than corresponding those (2.403-2.425 $\AA$; $2.475-2.533 \AA$ ) in cluster1. The aforementioned values indicate that the $\mathrm{Pd}-\mathrm{Ge}$ bonds are relatively strong in the $\mathrm{Ge} @ \mathrm{Pd}_{3}$ sheet of cluster-1/2. Additionally, the Pd-P distances $(2.306-2.320 \AA$ for $1 ; 2.295-2.317 \AA$ for 2$)$ are well comparable to that $(2.306 \AA)$ in $\left[\left(\mathrm{Me}_{3} \mathrm{Si}\right) \mathrm{Si}_{3} \mathrm{EtGe}_{9} \mathrm{Pd}\left(\mathrm{PPh}_{3}\right)\right.$
${ }^{29}$, but relatively longer than those in $\left[\mathrm{Ge}_{9} \mathrm{PdPPh}_{3}\right]^{3-}(2.237 \AA)$ and $\left[\mathrm{Ni} @\left(\mathrm{Ge}_{9} \mathrm{PdPPh}_{3}\right)\right]^{2-}(2.235 \AA)^{27}$. The interplanar spacing between triangular faces (Ge1-3 and Ge11-13; Ge21-23 and Ge31-33) and Ge@Pd 3 planar fragment are almost identical (1: 2.366 and $2.342 \AA$, respectively; 2 : 2.347 and $2.349 \AA$, respectively) and considerably short. In turn, in cluster-1/2, the bonding 
a

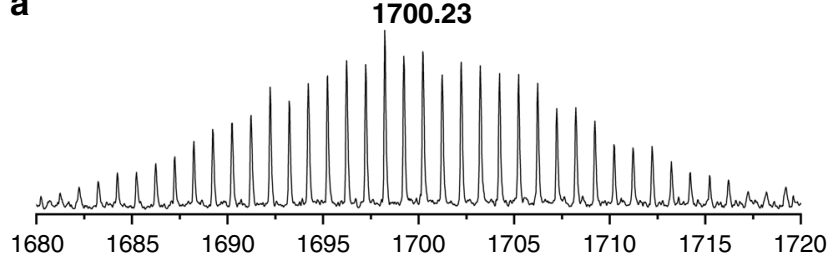

1700.23

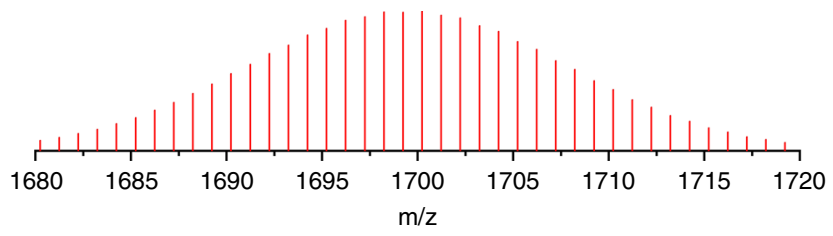

b

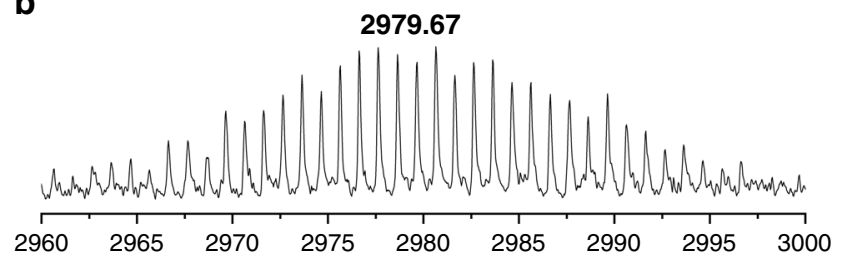

Fig. 3 Negative-ion ESI mass spectra. a Spectrum of $\left\{\left(\mathrm{Ge}_{9}\right)_{2}\left[\eta^{6}-\mathrm{GePd}_{3}\right]\right\}^{-}$fragment. b Spectrum of $\left\{\left[\mathrm{K}_{3}(2,2,2-\mathrm{crypt})\right]\left\{\left(\mathrm{Ge}_{9}\right)_{2}\left[\eta^{6}-\mathrm{Ge}\left(\mathrm{PdPPh}_{3}\right)_{3}\right]\right\}^{-}\right.$ fragment. Top: measured spectrum. Bottom: calculated spectrum.

interaction between the two $\mathrm{Ge}_{9}$ moieties and the central $\mathrm{Ge}$ is very weak due to the long bond distances (1: 2.795-2.906 $\AA$; 2 : 2.778-2.905 $\AA$, see the Supplementary Data 1). The Pd...Pd distances, 3.959-4.325 $\AA$ for 1 and 3.988-4.260 $\AA$ for 2, are far from the range of normal Pd-Pd bond lengths $(2.53-2.70 \AA)^{30,31}$, which means that there is no bond interaction between Pd-atoms.

In addition, the electrospray ionization mass spectrometry (ESI-MS) on a DMF solution of the crystals of $[\mathrm{K}(2,2,2-$ crypt $)]_{4}\left\{\left(\mathrm{Ge}_{9}\right)_{2}\left[\eta^{6}-\mathrm{Ge}\left(\mathrm{PdPPh}_{3}\right)_{3}\right]\right\}$ was performed in negativeion mode to observe a series of fragments from the parent compound. Although several strong peaks were shown clearly and identified as $\left\{\left(\mathrm{Ge}_{9}\right)_{2}\left[\eta^{6}-\mathrm{GePd}_{3}\right]\right\}^{-}(1700.23$, Fig. 3a), $\left\{\left[\mathrm{K}_{3}(2,2,2-\mathrm{crypt})\right]\left\{\left(\mathrm{Ge}_{9}\right)_{2}\left[\eta^{6}-\mathrm{Ge}\left(\mathrm{PdPPh}_{3}\right)_{3}\right]\right\}^{-}(2979.67\right.$, Fig. 3b) and other parent compound peaks (Supplementary Fig. 4), any other peaks of small fragments were almost invisible in the range of the measured spectrum. The result may indicate the stability of title compound in solution.

Structure and chemical bonding. The computationally optimized structure of $\left\{\left(\mathrm{Ge}_{9}\right)_{2}\left[\eta^{6}-\mathrm{Ge}\left(\mathrm{PdPPh}_{3}\right)_{3}\right]\right\}^{4-}$ is in agreement with the X-Ray characterized structure denoting $\eta^{6}-\mathrm{Ge}-\mathrm{Ge}$ distances of $2.905 \AA, \eta^{6}-\mathrm{Ge}-\mathrm{Pd}$ of $2.462 \AA$, and Ge-Pd of $2.530 \AA$. The calculated Pd-Pd distances are $4.324 \AA$, which is larger than the sum of their van der Waals radius $(\sim 4.1 \AA)^{32}$ indicating the absence of Pd-Pd two-center bonds. Thus, the central moiety can be better described as a $s p^{2}-\mathrm{Ge} @\left(\mathrm{PdPPh}_{3}\right)_{3}$ trigonal planar structure, rather than a $\mathrm{Pd}_{3}$ ring. The electronic structure of $\left\{\left(\mathrm{Ge}_{9}\right)_{2}\left[\eta^{6}-\mathrm{Ge}\left(\mathrm{PdPPh}_{3}\right)_{3}\right]\right\}^{4-}$ shows a sizable frontier orbital gap as a result of bringing together two closo- $\mathrm{Ge}_{9}{ }^{2-}$ units with a slightly distorted $D_{3 \mathrm{~h}}$ geometry mediated by a bridging moiety. Such behavior suggests that each closo- $\left[\mathrm{Ge}_{9}\right]^{2-}$ unit in $\left\{\left(\mathrm{Ge}_{9}\right)_{2}\left[\eta^{6}-\right.\right.$ $\left.\left.\mathrm{Ge}\left(\mathrm{PdPPh}_{3}\right)_{3}\right]\right\}^{4-}$ exhibits spherical aromatic properties. Notably, it was previously shown, that the bare $\left[\mathrm{Ge}_{9}\right]^{2-}$ shows spherically aromatic properties, and $\left[\mathrm{Ge}_{9}\right]^{4-}$ clusters are locally $\sigma-$ aromatic $^{33,34}$.

The presence of two $\left[\mathrm{Ge}_{9}\right]^{2-}$ ligands and the overall charge of the complex -4 push us to the conclusion that the formal charge of the central Ge@ $\left(\mathrm{PdPPh}_{3}\right)_{3}$ fragment as 0 . To show this, the charge distribution was calculated using the natural bond orbitals (NBO) analysis. The results are shown in Fig. 4. It was found that the overall charges of $\mathrm{Ge}_{9}$ fragments are -1.6 a.u., while the central Ge-atom bears slightly positive close to zero charge, which were classically found in organogermanium complexes and stabilized by carbine ligands that donate electron pairs into their empty orbitals ${ }^{35-39}$. Thus, the natural population analysis is in a

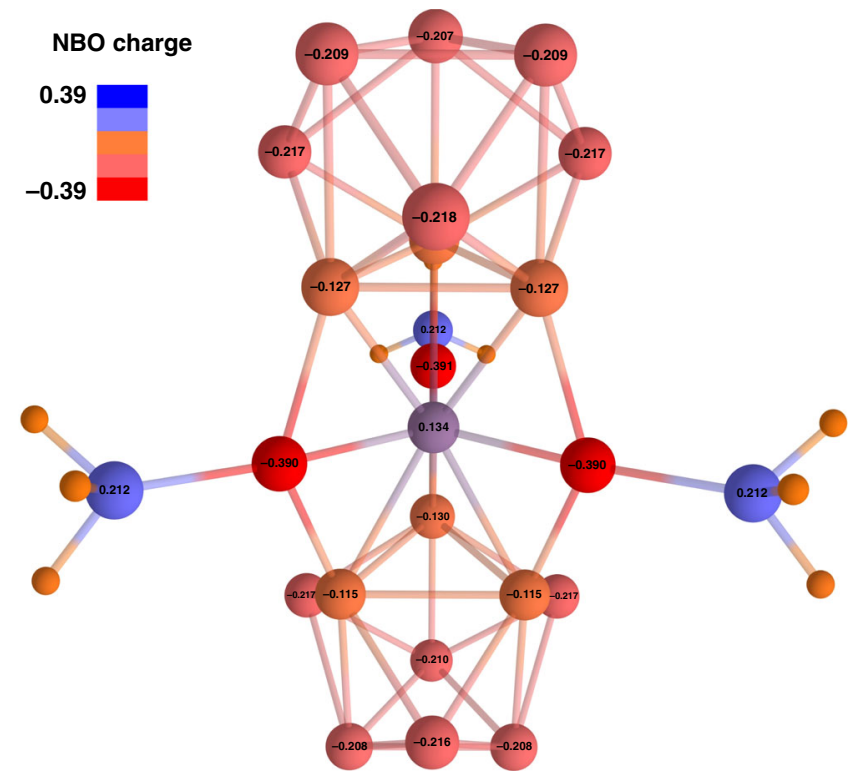

Fig. 4 The charge distribution calculated via NBO method. Positive and negative charges are illustrated in a scale form blue to red, respectively. Lines between atoms help in visualization and do not represent $2 \mathrm{c}-2 \mathrm{e}$ bonds here and elsewhere. Charges of hydrogen atoms are omitted for clarity.

good agreement with our assumption of zerovalent central Geatom stabilized by two $\left[\mathrm{Ge}_{9}\right]^{2-}$ ligands. Notably, the Pd-atoms have a partially negative charge, which could be explained by the donor-acceptor nature of two-center two-electron (2c-2e) Pd-P bonds. In turn, the formal oxidation state of Pd-atoms is 0 . The complete table with natural charges could be found in the Supplementary Information file (Supplementary Table 2).

To gain insights on the chemical bonding pattern of $\left\{\left(\mathrm{Ge}_{9}\right)_{2}\left[\eta^{6}-\mathrm{Ge}\left(\mathrm{PdPPh}_{3}\right)_{3}\right]\right\}^{4-}$ cluster, we performed the adaptive natural density partitioning (AdNDP) analysis ${ }^{40}$ as implemented in the AdNDP 2.0 code $^{41}$ of a model $\left\{\left(\mathrm{Ge}_{9}\right)_{2}\left[\eta^{6}-\mathrm{Ge}\right.\right.$ $\left.\left.\left(\mathrm{PdPH}_{3}\right)_{3}\right]\right\}^{4-}$ cluster (the phenyl substituents were replaced by hydrogen atoms; such substitution does not affect the bonding of the central fragment). The model complex contains 134 valence electrons, which can be localized to 67 two-electron bonding elements. Starting our search from one-center twoelectron elements, the algorithm revealed the presence of lone 
a

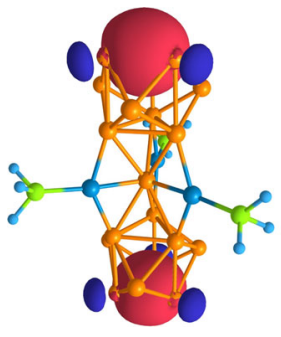

Two 3c-2e bonds $\mathrm{ON}=1.97|\mathrm{e}|$

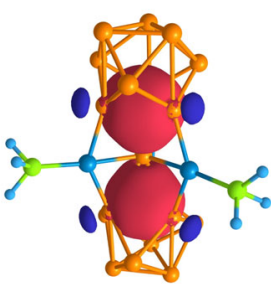

Two 4c-2e bonds $\mathrm{ON}=1.95|\mathrm{e}|$

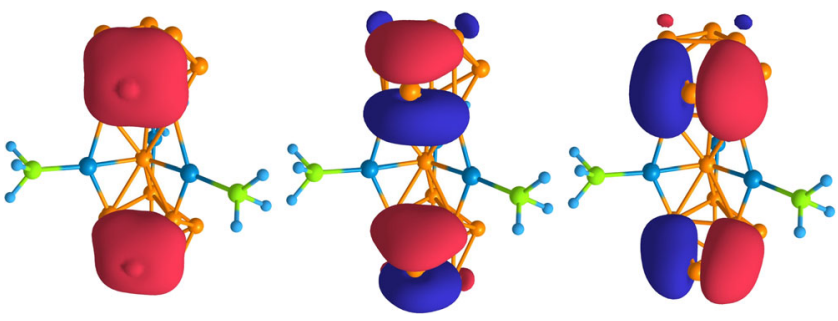

Eighteen $5 \mathrm{c}-2 \mathrm{e}$ bonds

(Three per cap, only two sets are shown) $\mathrm{ON}=1.94-1.84|\mathrm{e}|$

b

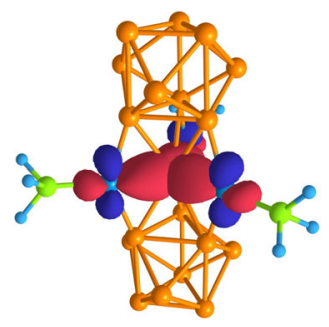

Three 2c-2e Pd-Ge $\sigma$-bonds $\mathrm{ON}=1.95|\mathrm{e}|$ $\mathrm{ON}=1.95|\mathrm{e}|$

Fig. 5 The result of AdNDP analysis of the selected fragments of the cluster-1. a Multicenter bonds of $\left\{\left(\mathrm{Ge}_{9}\right)_{2}\left[\eta^{6}-\mathrm{Ge}\left(\mathrm{PdPH}_{3}\right)_{3}\right]\right\}^{4-}$. b Localized $2 \mathrm{c}-2 \mathrm{e}$ bonds of $\left\{\left(\mathrm{Ge}_{9}\right)_{2}\left[\eta^{6}-\mathrm{Ge}\left(\mathrm{PdPH}_{3}\right)_{3}\right]\right\}^{4-}$.

pairs on the Germanium and Palladium atoms (Supplementary Fig. 15). Thus, twelve s-type lone pairs on Ge-atoms with occupancy numbers (ONs) 1.89-1.87 | e| and twelve $d$-type lone pairs (four lone pairs per each atom) on Pd-atoms with ONs 1.98-1.91 | e| were localized. Further localization showed the presence of twenty-one 2c-2e bonds (Fig. 5b, Supplementary Fig. 15). Predictably, we found a completely classical bonding pattern for $\mathrm{PH}_{3}$ groups with three 2c-2e $\mathrm{P}-\mathrm{H} \sigma$-bonds per each group. In turn, the $\mathrm{PH}_{3}$ groups attached to the $\mathrm{Pd}$-atoms by $2 \mathrm{c}-2 \mathrm{e}$ bonds with $\mathrm{ON}=1.99|\mathrm{e}|$ (contribution of $\mathrm{P}$-atoms is $\sim 86 \%)$. The planar fragment consists of three $2 \mathrm{c}-2 \mathrm{e} \mathrm{Pd}-\mathrm{Ge} \sigma-$ bonds attaching $\mathrm{Pd}$-atoms to the central $\mathrm{Ge}$-atom, and six $2 \mathrm{c}-2 \mathrm{e} \mathrm{Pd}-\mathrm{Ge} \sigma$-bonds bind the $\mathrm{Ge} @ \mathrm{Pd}_{3}$ planar fragment and $\mathrm{Ge}_{9}$ fragments (contribution of $\mathrm{Ge}$-atoms is $\sim 77 \%$ ). The binding interactions within the planar fragment found by the AdNDP are consistent with the ELF topology analysis (Supplementary Fig. 16).

Further molecular orbital analysis, as given by the molecular orbital diagram of the $\left(\mathrm{Ge}_{9}\right)_{2}{ }^{4-}-\mathrm{Ge}\left(\mathrm{PdPPh}_{3}\right)_{3}$ interaction (Supplementary Figs. 19, 20), shows several bonding contributions involving mainly $\pi$-radial orbitals from the $\left(\mathrm{Ge}_{9}\right)_{2}{ }^{4-}$ fragment. The HOMO orbital is given by the bonding interaction between a $p_{\mathrm{z}}$-Ge based orbital from the central Ge-atom, and the pertinent $\pi$-radial orbitals from the $\mathrm{Ge}_{9}$ clusters. A bonding interaction
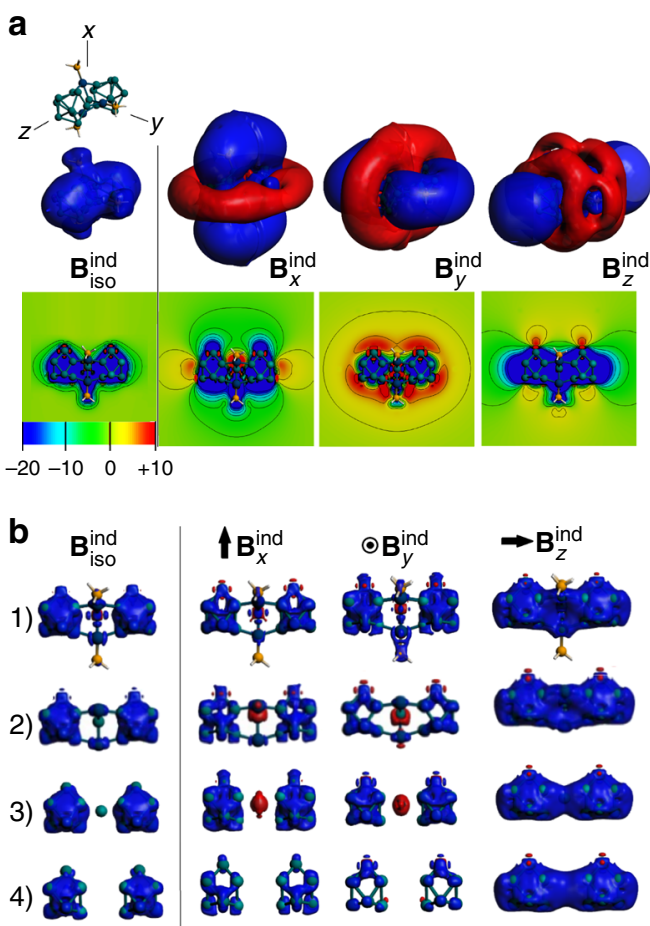

Fig. 6 Plots and isosurfaces of magnetic response of the studied cluster. a Induced magnetic field of the studied cluster involving an orientation averaged ( $B^{\text {ind }}{ }_{\text {iso }}$ ) and orientations of the external field along three representative axes. Isovalue set to $\pm 2 \mathrm{ppm}$ (top). The cut-plane representations are given (bottom). Blue: shielding; Red: Deshielding surfaces. b Shielding surfaces (35 ppm) for $\left\{\left(\mathrm{Ge}_{9}\right)_{2}\left[\eta^{6}-\mathrm{Ge}\left(\mathrm{PdPH}_{3}\right)_{3}\right]\right\}^{4-}$ (1), the unligated core $\left\{\left(\mathrm{Ge}_{9}\right)_{2}\left[\eta^{6}-\mathrm{GePd}_{3}\right]\right\}^{4-}(2)$, the core without Pd-atoms $\left\{\left(\mathrm{Ge}_{9}\right)_{2}\left[\eta^{6}-\mathrm{Ge}\right]\right\}^{4-}(3)$, and the non-bridged species $\left[\mathrm{Ge}_{9} \mathrm{Ge}_{9}\right]^{4-}$ (4).

between $\mathrm{Ge}_{9}$ clusters and $d$-Pd-atoms could be seen from HOMO-2 and HOMO-3, which in turn enhance the $\sigma-\mathrm{Ge}_{3} \mathrm{Pd}_{3}$ interaction. Such bonding interactions are well summarized by the localized bonds provided by the AdNDP analysis, showing three $\sigma-\mathrm{Ge} @ \mathrm{Pd}$ bonds based on the $d$-Pd interacting orbitals with the $\mathrm{Ge}_{9}$ clusters, and six 2c-2e Pd-Ge (Fig. 5b).

Further localization showed that the $\mathrm{Ge}_{9}$ fragments possess $\sigma$-aromatic character (with locally $\sigma$-aromatic $\mathrm{Ge}_{5}$-caps and $\mathrm{Ge}_{3}$-triangles, Fig. 5a). Notably, almost identical chemical bonding pattern was described in our previous work for nonagermanide clusters ${ }^{34}$. The main difference is the presence of $4 c-2 e$ bonds that bound the central Ge-atom and two $\mathrm{Ge}_{9}$ units, which partially present in the HOMO and HOMO-1 (Supplementary Fig. 17). We want to note that the same delocalization with the formation of the $4 \mathrm{c}-2 \mathrm{e}$ bond (that contributes to bonding interaction) was found for coppercontaining nonagermanide clusters such as $\mathrm{Cu}\left[\mathrm{Ge}_{9}\left\{\mathrm{P}\left(\mathrm{NH}_{2}\right)_{2}\right\}_{3}\right]$, $\mathrm{Cu}(\mathrm{NHC})\left[\mathrm{Ge}_{9}\left\{\mathrm{P}\left(\mathrm{NH}_{2}\right)_{2}\right\}_{3}\right]^{-}$, and $\left\{\left[\mathrm{Ge}_{9}\left\{\mathrm{P}\left(\mathrm{NH}_{2}\right)_{2}\right\}_{3}\right] \mathrm{Cu}\left[\mathrm{Ge}_{9}\{\mathrm{P}\right.\right.$ $\left.\left.\left.\left(\mathrm{NH}_{2}\right)_{2}\right\}_{3}\right]\right\}^{-34}$. Hence, the two $4 \mathrm{c}-2 \mathrm{e}$ bonds have the main role in the stabilization of the zerovalent germanium atom. As a result, a charge donation to the empty Ge- $p_{z}$ atomic orbital occurs, favoring the sandwich-like incorporation and charge state stabilization.

Moreover, analysis of the magnetic response of $\left\{\left(\mathrm{Ge}_{9}\right)_{2}\left[\eta^{6}-\mathrm{Ge}\right.\right.$ $\left.\left.\left(\mathrm{PdPH}_{3}\right)_{3}\right]\right\}^{4-}$ reveals a spherical-like shielding surface at both $\mathrm{Ge}_{9}$ units as a characteristic feature of spherically aromatic compounds, as obtained from an orientation averaged applied field which accounts for the isotropic response ( $\mathrm{B}_{\text {ind }}$ ) owing to the constant molecular tumbling in solution (Fig. 6a). The 
spherical aromatic characteristic of each $\mathrm{Ge}_{9}$ subunit is provided by the arrangement of locally $\sigma$-aromatic regions revealed by the AdNDP analysis (vide supra). The aromatic nature of nonegermanide subunits remains after the $\mathrm{Ge}_{9}-\mathrm{Ge}_{0} \mathrm{Pd}_{3}$ interaction, and their structural features are close to a closo- $D_{3 \mathrm{~h}}$-ttp cage. This result denotes that the overall cluster can be considered as twospherical aromatic clusters held together by the central Ge@ $\left(\mathrm{PdPPh}_{3}\right)_{3}$. Under a specific orientation of the applied field $\left(\mathrm{B}^{\text {ind }}{ }_{x}\right.$, $\mathrm{B}^{\text {ind }}{ }_{y}$ or $\mathrm{B}^{\text {ind }}{ }_{z}$ ), the distinctive shielding cone property for aromatic species is obtained at each $\mathrm{Ge}_{9}$ unit. For a perpendicular orientation in relation to the $\mathrm{Ge}_{9}-\mathrm{Ge}-\mathrm{Ge}_{9}$ axis $\left(\mathrm{B}^{\text {ind }}{ }_{x}\right.$ and $\mathrm{B}^{\text {ind }}{ }_{y}$ ), a shielding region is obtained which sum together in a common region of about $-3.75 \mathrm{ppm}$ (Figs. 6a, 2), which separate into independent parallel cones at isosurfaces above $\pm 4 \mathrm{ppm}$ together, being complemented with a deshielding region (Fig. 6b). Interestingly, for a parallelly oriented field along $\mathrm{Ge}_{9}-\mathrm{Ge}_{-} \mathrm{Ge}_{9}$ axis $\left(\mathrm{B}^{\text {ind }}{ }_{z}\right)$, two shielding cones are obtained, which overlap the shielding region at the central $\mathrm{Ge}\left(\mathrm{PdPPh}_{3}\right)_{3}$, originated from each $\mathrm{Ge}_{9}$ sides, denoting two separated complementary deshielding regions at the $\mathrm{Ge}_{9}$ belt.

From Fig. 6a, it is shown that $\left\{\left(\mathrm{Ge}_{9}\right)_{2}\left[\eta^{6}-\mathrm{Ge}\left(\mathrm{PdPH}_{3}\right)_{3}\right]\right\}^{4-}$ is able to sustain a shielding cone upon different orientations of the applied field centered at each $\mathrm{Ge}_{9}$ unit, which is a distinctive feature of spherical aromatic compounds in contrast to planar counterparts, where is sustained under a parallel orientation (for example benzene, Supplementary Fig. 18). At different orientations, the shielding region is originated at each $\mathrm{Ge}_{9}$ unit, as can be seen from larger isosurface values $(> \pm 35 \mathrm{ppm}$, Fig. $6 \mathrm{~b}$ ) denoting the isotropic term $\left(\mathrm{B}^{\text {ind }}{ }_{\text {iso }}\right)$, and from perpendicular orientation in relation to the $\mathrm{Ge}_{9}-\mathrm{Ge}-\mathrm{Ge}_{9}$ axis $\left(\mathrm{B}^{\text {ind }}{ }_{x}\right.$ and $\left.B^{\text {ind }}{ }_{y}\right)$. Moreover, for a field oriented along the $\mathrm{Ge}_{9}-\mathrm{Ge}-\mathrm{Ge}_{9}$ axis $\left(\mathrm{B}^{\text {ind }}\right)$ besides the shielding region $(>-35 \mathrm{ppm})$ at each nonagermanide units, a shielding region involving each capped $\mathrm{Ge}_{3}$ face from $\mathrm{Ge}_{9}$ and the bridging $\mathrm{Ge} @ \mathrm{Pd}_{3}$ group was observed, which suggests a potential planar aromatic behavior in the $\mathrm{Ge}_{3}-\mathrm{Ge} @ \mathrm{Pd}_{3}-\mathrm{Ge}_{3}$ fragment as a result of the $\mathrm{Ge}_{9}-\mathrm{Ge}$ $\left(\mathrm{PdPPh}_{3}\right)_{3}-\mathrm{Ge}_{9}$ bonding interaction. However, further inspection for $\left\{\left(\mathrm{Ge}_{9}\right)_{2}\left[\eta^{6}-\mathrm{Ge}\left(\mathrm{PdPH}_{3}\right)_{3}\right]\right\}^{4-}$ in comparison to the unligated core $\left\{\left(\mathrm{Ge}_{9}\right)_{2}\left[\eta^{6}-\mathrm{GePd}_{3}\right]\right\}^{4-}$, the core by removing Pd-atoms $\left\{\left(\mathrm{Ge}_{9}\right)_{2}\left[\eta^{6}-\mathrm{Ge}\right]\right\}^{4-}$, and the non-bridged species $\left[\mathrm{Ge}_{9}, \ldots \mathrm{Ge}_{9}\right]^{4-}$, shows that the shielding contribution is originated from the spherical aromatic $\mathrm{Ge}_{9}{ }^{2-}$ units mainly, supporting the description of $\left\{\left(\mathrm{Ge}_{9}\right)_{2}\left[\eta^{6}-\mathrm{Ge}\left(\mathrm{PdPPh}_{3}\right)_{3}\right]\right\}^{4-}$ as a cluster with two-bridged spherical aromatic units.

\section{Discussion}

In summary, we report a synthesis of $\left\{\left(\mathrm{Ge}_{9}\right)_{2}\left[\eta^{6}-\mathrm{Ge}\left(\mathrm{PdPPh}_{3}\right)_{3}\right]\right\}^{4-}$ that represents the peculiar sandwich-type species containing a heterometallic Ge@Pd $\mathrm{Pd}_{3}$ planar fragment in which the germanium core of zero oxidation state is stabilized in the sandwich framework. Unlike prior weak metal-metal interactions in the interlayer, such as the $\mathrm{Au}_{3}$ ring of $\left[\mathrm{Sb}_{3} \mathrm{Au}_{3} \mathrm{Sb}_{3}\right]^{3-15}$, the heterometallic $\mathrm{Ge} @ \mathrm{Pd}_{3}$ is formed by strong Pd-Ge bonding interactions, which may play a vital role in its properties. The AdNDP and ELF analyses reveal the presence of three $2 c-2 e$ bonds attaching Pd-atoms to the central Ge-atom in the Ge@Pd 3 triangle and six 2c-2e bonds between Pd-atoms and two $\mathrm{Ge}_{9}$ units. Two $4 \mathrm{c}-2 \mathrm{e}$ bonds between $\mathrm{Ge}_{9}$ units and central Ge-atom have the main role in the stabilization of the zerovalent germanium. The analysis of the magnetic response exhibits that the overall cluster can be considered as two spherically aromatic fragments held together by the central $\mathrm{Ge}\left(\mathrm{PdPPh}_{3}\right)_{3}$ group.

The $\left\{\left(\mathrm{Ge}_{9}\right)_{2}\left[\eta^{6}-\mathrm{Ge}\left(\mathrm{PdPPh}_{3}\right)_{3}\right]\right\}^{4-}$ complex expands the borders of possible sandwich compounds showing that the metal interlayer can be formed by different metal elements, including transition metals and main group metals. We believe that the heterometallic planar fragment can bring some fascinating properties to new sandwich species, which provides more opportunities for new applications of sandwich complexes.

\section{Methods}

Synthesis of $[K(2,2,2-c r y p t)]_{4}\left\{\left(G_{e_{9}}\right)_{2}\left[\eta^{6}-G e\left(P_{P P P h}\right)_{3}\right]\right\}$. All manipulations and reactions were performed under a dry nitrogen atmosphere in a glove box. Ethylenediamine (Aldrich, 99\%) and toluene (Aldrich, 99.8\%) were freshly distilled and stored under nitrogen prior to use. 2,2,2-crypt $(4,7,13,16,21,24$ Hexaoxa-1,10-diazabicyclo (8.8.8) hexacosane, purchased from Acros, 98\%), (Triphenylphosphoranylidene)acetonitrile (aladdin, $>98 \%$ ) and $\mathrm{Pd}\left(\mathrm{PPh}_{3}\right)_{4}(\mathrm{Alfa}-$ Aesar, $99 \%$ ) was dried in vacuum for $12 \mathrm{~h}$ prior to use. The precursor $\mathrm{K}_{4} \mathrm{Ge}_{9}$ was synthesized by heating a stoichiometric mixture of the elements (K: $386 \mathrm{mg}$, Ge: $1.614 \mathrm{~g} ; \mathrm{K}:+99 \%$, Ge: $99.999 \%$, all from Strem) at a rate of $50^{\circ} \mathrm{C}$ per hour to $900^{\circ} \mathrm{C}$ and keeping it for 3 days in sealed niobium containers closed in evacuated quartz ampules. The furnace was slowly cooled to room temperature at a rate of $50{ }^{\circ} \mathrm{C}$ per hour ${ }^{42}$. The $\mathrm{K}_{4} \mathrm{Ge}_{9}$ solid was obtained with a high yield $(\sim 90 \%$, $1.8 \mathrm{~g}$ ) and stored under a dry nitrogen atmosphere in a glove box. In a glass vial, $81 \mathrm{mg}(0.1 \mathrm{mmol})$ of $\mathrm{K}_{4} \mathrm{Ge}_{9}$ and $100 \mathrm{mg}(0.27 \mathrm{mmol})$ of 2,2,2-crypt were dissolved in ethylenediamine $(1.5 \mathrm{~mL})$. After stirring for $15 \mathrm{~min}$, the brown solution was filtered onto $36.2 \mathrm{mg}(0.12 \mathrm{mmol})$ of (Triphenylphosphoranylidene)acetonitrile. After $0.5 \mathrm{~h}$ at $55^{\circ} \mathrm{C}$, the brown solution was added slowly to a $0.5 \mathrm{~mL}$ toluene solution of $92.4 \mathrm{mg}(0.08 \mathrm{mmol})$ of $\mathrm{Pd}\left(\mathrm{PPh}_{3}\right)_{4}$ and vigorously stirred for $1 \mathrm{~h}$ at room temperature, and then another $92.4 \mathrm{mg}$ of $\mathrm{Pd}\left(\mathrm{PPh}_{3}\right)_{4}$ was added. After $3 \mathrm{~h}$ at room temperature, the reaction mixture was filtered through glass wool and layered with $3 \mathrm{~mL}$ toluene. After 17 days, black needle-like crystals of $[\mathrm{K}(2,2,2 \text {-crypt })]_{4}\left\{\left(\mathrm{Ge}_{9}\right)_{2}\left[\eta^{6}-\mathrm{Ge}\left(\mathrm{PdPPh}_{3}\right)_{3}\right]\right\}$ was observed in the test tube $(33 \mathrm{mg}$, $17 \%$ yield based on $\mathrm{K}_{4} \mathrm{Ge}_{9}$ ).

Theoretical methods. Geometry optimization and frequency calculations were performed using Gaussian 16 software package ${ }^{43}$. Optimized geometries, total energies are reported at the PBE0/Def2-TZVP level of theory ${ }^{44,45}$. The DFT wave functions were found to be stable, so the DFT approximation is valid. To understand the chemical bonding of investigated species, we carried out electron localization analysis at the same level of theory using the AdNDP method as implemented in the AdNDP 2.0 code $^{40,41}$. ELF calculations were performed via MultiWFN software ${ }^{46,47}$. In addition, the isosurface and cut-plane representation of the induced magnetic field ( $B^{\text {ind }}$ ) was obtained within the GIAO formalism at the relativistic ZORA-PBE0/TZ2P level of theory by using the ADF suite unraveling the long-range characteristics of the magnetic response $e^{48,49}$

Crystallographic methods. Suitable crystals from the $[\mathrm{K}(2,2,2-\mathrm{crypt})]_{4}\left\{\left(\mathrm{Ge}_{9}\right)_{2}\left[\eta^{6}\right.\right.$ $\left.\left.\mathrm{Ge}\left(\mathrm{PdPPh}_{3}\right)_{3}\right]\right\}$ were selected for X-ray diffraction analyses. Crystallographic data were collected on a Rigaku XtalAB Pro MM007 DW diffractometer (Cu-Mo Ka radiation) at $100 \mathrm{~K}$. The structure of the crystal was solved using direct methods and then refined using SHELXL-2014 and Olex2 ${ }^{50-52}$, in which all the nonhydrogen atoms were refined anisotropically. All hydrogen atoms of organic groups were rationally placed by geometrical considerations. The K2 and K8 were refined anisotropically and show an abnormal thermal motion that could not be resolved by using restraints. The limitation of data quality leads to the low bond precision on $\mathrm{C}-\mathrm{C}$ bonds, and large cell volume also makes it not easy to obtain better data. The uncoordinated solvent molecules could not be modeled properly, so the PLATON SQUEEZE procedure was used during the refinement to remove the solvent molecules ${ }^{53}$.

Energy dispersive X-ray (EDX). EDX Analysis was performed using a scanning electron microscope (Hitachi S-4800) equipped with a Bruker AXS XFlash detector 4010. Data acquisition was performed with an acceleration voltage of $20 \mathrm{kV}$ and an accumulation time of $150 \mathrm{~s}$

\section{Data availability}

The data that support the findings of this study are available from the corresponding authors on a reasonable request. The X-ray crystallographic coordinates for structures reported in this study have been deposited at the Cambridge Crystallographic Data Centre (CCDC), under deposition number 1997656. These data can be obtained free of charge from The Cambridge Crystallographic Data Centre via www.ccdc.cam.ac.uk/ data_request/cif.

Received: 5 May 2020; Accepted: 14 September 2020; Published online: 20 October 2020 


\section{References}

1. Kealy, T. J. \& Pauson, P. L. A new type of organo-iron compound. Nature 168, 1039-1040 (1951).

2. Wilkinson, G., Rosenblum, M., Whiting, M. C. \& Woodward, R. B. The structure of iron bis-cyclopentadienyl. J. Am. Chem. Soc. 74, 2125-2126 (1952).

3. Fischer, E. O. \& Pfab, W. Cyclopentadiene-metallic complex, a new type of organo-metallic compound. Z. Naturforsch. B 7, 377-379 (1952).

4. Togni, A. \& Halterman, R. L. (eds) Metallocenes: Synthesis reactivity applications (Wiley-VCH, Weinheim, 1998).

5. Garnovskii, A. D., Sadimenko, A. P., Sadimenko, M. I. \& Garnovskii, D. A. Common and less-common coordination modes of the typical chelating and heteroaromatic ligands. Coord. Chem. Rev. 173, 31-77 (1998).

6. Scherer, O. J. Complexes with substituent-free acyclic and cyclic phosphorus, arsenic, antimony, and bismuth ligands. Angew. Chem. Int. Ed. 29, 1104-1122 (1990).

7. Malar, E. J. P. Study of aromaticity in phosphorus analogs of cyclopentadienyl anion. J. Org. Chem. 57, 3694-3698 (1992).

8. Dransfeld, A., Nyulaszi, L. \& Schleyer, Pv. R. The aromaticity of polyphosphaphospholes decreases with the pyramidality of the tricoordinate phosphorus. Inorg. Chem. 37, 4413-4420 (1998).

9. Urnezius, E., Brennessel, W. W., Cramer, C. J., Ellis, J. E. \& Schleyer, Pv. R. A carbon-free sandwich complex $\left[\left(\mathrm{P}_{5}\right)_{2} \mathrm{Ti}\right]^{2-}$. Science 295, 832-834 (2002).

10. Murahashi, T. et al. Discrete sandwich compounds of monolayer palladium sheets. Science 313, 1104-1107 (2006).

11. Murahashi, T. et al. Redox-induced reversible metal assembly through translocation and reversible ligand coupling in tetranuclear metal sandwich frameworks. Nat. Chem. 4, 52-58 (2012).

12. Teramoto, M. et al. Three-dimensional sandwich nanocubes composed of 13atom Palladium core and hexakis-carbocycle shell. J. Am. Chem. Soc. 140, 12682-12686 (2018).

13. Ishikawa, T. et al. Exceeding metal capacity in sandwich complexes: ligandunsupported docking of extra metal moieties at edges of a metal sheet sandwich complex. Angew. Chem. Int. Ed. 58, 15318-15323 (2019).

14. Muetterties, E. L., Rhodin, T. N., Band, E., Brucker, C. F. \& Pretzer, W. R Clusters and surfaces. Chem. Rev. 79, 91-137 (1979).

15. Pan, F. X. et al. An all-metal aromatic sandwich complex $\left[\mathrm{Sb}_{3} \mathrm{Au}_{3} \mathrm{Sb}_{3}\right]^{3-}$. J. Am. Chem. Soc. 137, 10954-10957 (2015).

16. Spiekermann, A., Hoffmann, S. D., Kraus, F. \& Fässler, T. F. $\left[\mathrm{Au}_{3} \mathrm{Ge}_{18}\right]^{5-}-\mathrm{a}$ gold-germanium cluster with remarkable $\mathrm{Au}-\mathrm{Au}$ interactions. Angew. Chem. Int. Ed. 46, 1638-1640 (2007).

17. Perla, L. G. \& Sevov, S. C. A stannyl-decorated Zintl ion $\left[\mathrm{Ge}_{18} \mathrm{Pd}_{3}\left(\mathrm{Sn}^{\mathrm{i} P \mathrm{Pr}_{3}}\right)_{6}\right]^{2-}$ : twinned icosahedron with a common $\mathrm{Pd}_{3}$-face or 18-vertex hyphodeltahedron with a $\mathrm{Pd}_{3}$-triangle inside. J. Am. Chem. Soc. 138, 9795-9798 (2016).

18. Perla, L. G., Muñoz-Castro, A. \& Sevov, S. C. Eclipsed- and staggered$\left[\mathrm{Ge}_{18} \mathrm{Pd}_{3}\left\{\mathrm{E}^{\mathrm{i}} \mathrm{Pr}_{3}\right\}_{6}\right]^{2-}(\mathrm{E}=\mathrm{Si}, \mathrm{Sn})$ : positional isomerism in deltahedral Zintl clusters. J. Am. Chem. Soc. 139, 15176-15181 (2017).

19. Ugrinov, A. \& Sevov, S. C. $\left[\mathrm{Ge}_{9}=\mathrm{Ge}_{9}=\mathrm{Ge}_{9}\right]^{6-}:$ A linear trimer of 27 germanium atoms. J. Am. Chem. Soc. 124, 10990-10991 (2002).

20. Sevov, S. C. \& Goicoechea, J. M. Chemistry of deltahedral Zintl ions. Organometallics 25, 5678-5692 (2006).

21. Alvarez, S. et al. Shape maps and polyhedral interconversion paths in transition metal chemistry. Coord. Chem. Rev. 249, 1693-1708 (2005).

22. Cirera, J., Ruiz, E. \& Alvarez, S. Continuous shape measures as a stereochemical tool in organometallic chemistry. Organometallics $\mathbf{2 4}$, 1556-1562 (2005).

23. Åkerstedt, J. et al. Structural investigation of a fully ordered closo-Ge ${ }_{9}{ }^{2-}$ cluster in the compound $[\mathrm{K}+(2,2,2-\mathrm{crypt})]_{2} \mathrm{Ge}_{9}{ }^{2-}$. Eur. J. Inorg. Chem. 2011, 3999-4005 (2011).

24. Liu, C. \& Sun, Z. M. Recent advances in structural chemistry of group 14 Zintl ions. Coord. Chem. Rev. 382, 32-56 (2019).

25. Hauptmann, R. \& Fässler, T. F. Z. Low dimensional arrangements of the Zint ion $\left[\mathrm{Ge}_{9}-\mathrm{Ge}_{9}\right]^{6-}$ and chemical bonding in $\left[\mathrm{Ge}_{6}\right]^{2-},\left[\mathrm{Ge}_{9}-\mathrm{Ge}_{9}\right]^{6-}$, and $\left\{\left[\mathrm{Ge}_{9}\right]\right\}^{2-}$. Z. Anorg. Allg. Chem. 629, 2266-2273 (2003).

26. Nienhaus, A., Hoffmann, S. D. \& Fässler, T. F. First synthesis of group-14 polyanions by extraction of a binary alloy with $\mathrm{dmf}$ and a novel conformation of the $\left(\mathrm{Ge}_{9}-\mathrm{Ge}_{9}\right)^{6-}$ dimer: crystal structures of $\left[\mathrm{K}_{6}\left(\mathrm{Ge}_{9}-\mathrm{Ge}_{9}\right)\right](\mathrm{dmf})_{12}$, $\left[\mathrm{Rb}_{6}\left(\mathrm{Ge}_{9}-\mathrm{Ge}_{9}\right)\right](\mathrm{dmf})_{12}$ and $\left[\mathrm{K}_{2.5} \mathrm{Cs}_{3.5}\left(\mathrm{Ge}_{9}-\mathrm{Ge}_{9}\right)\right](\mathrm{dmf})_{12}$. Z. Anorg. Allg. Chem. 632, 1752-1758 (2006).

27. Li, F., MuÇoz-Castro, A. \& Sevov, S. C. $\left[\left(\mathrm{Me}_{3} \mathrm{Si}\right) \mathrm{Si}\right]_{3} \mathrm{EtGe}_{9} \mathrm{Pd}\left(\mathrm{PPh}_{3}\right)$, a pentafunctionalized deltahedral Zintl cluster: synthesis. Struct. Solut. Dyn. Angew. Chem. Int. Ed. 55, 8630-8633 (2016).

28. Sun, Z. M. et al. Diversity of functionalized germanium zintl clusters: syntheses and theoretical studies of $\left[\mathrm{Ge}_{9} \mathrm{PdPPh}_{3}\right]^{3-}$ and $\left[\mathrm{Ni} @\left(\mathrm{Ge}_{9} \mathrm{PdPPh}_{3}\right)\right]^{2-}$. J. Clust. Sci. 20, 601-609 (2009).

29. Goicoechea, J. M. et al. [(Pd-Pd)@Ge $\left.{ }_{18}\right]^{4-}:$ A palladium dimer inside the largest single-cage deltahedron. J. Am. Chem. Soc. 127, 7676-7677 (2005).
30. Dura'-Vila', V., Mingos, D. M. P., Vilar, R., White, A. J. P. \& Williams, D. J. Reactivity studies of $\left[\mathrm{Pd}_{2}(\mu-\mathrm{X})_{2}\left(\mathrm{PBu}_{3}^{\mathrm{t}}\right)_{2}\right](\mathrm{X}=\mathrm{Br}, \mathrm{I})$ with $\mathrm{CNR}(\mathrm{R}=2$, 6dimethylphenyl), $\mathrm{H}_{2}$ and alkynes. J. Organomet. Chem. 600, 198-205 (2000).

31. Vicente, J. et al. Synthesis and reactivity toward isonitriles of (2-aminoaryl) palladium (II) complexes. Organometallics 21, 272-282 (2002).

32. Batsanov, S. S. Van der waals radii of elements. Inorg. Mater. 37, 871-885 (2001).

33. Hirsch, A. et al. Spherical aromaticity of inorganic cage molecules. Angew. Chem. Int. Ed. 40, 2834-2838 (2001).

34. Tkachenko, N. V. \& Boldyrev, A. I. Multiple local $\sigma$-aromaticity of the nonagermanide clusters. Chem. Sci. 10, 5761-5765 (2019).

35. Li, Y. et al. Acyclic germylones: congeners of allenes with a central germanium atom. J. Am. Chem. Soc. 135, 12422-12428 (2013).

36. Rit, A., Campos, J., Niu, H. \& Aldridge, S. A stable heavier group 14 analogue of vinylidene. Nat. Chem. 8, 1022-1026 (2016).

37. Yun, X. et al. A cyclic germadicarbene ("germylone") from germyliumylidene. J. Am. Chem. Soc. 135, 5004-5007 (2013).

38. Zhou, Y. P. et al. A bis(silylenyl)pyridine zero-valent germanium complex and its remarkable reactivity. Angew. Chem. Int. Ed. 55, 1-5 (2016).

39. Majhi, P. K. et al. Tetrylones: an intriguing class of monoatomiczero-valent group 14 compounds. Chem. Eur. J. 24, 9441-9455 (2018).

40. Zubarev, D. Y. \& Boldyrev, A. I. Developing paradigms of chemical bonding: adaptive natural density partitioning. Phys. Chem. Chem. Phys. 10, 5207-5217 (2008).

41. Tkachenko, N. V. \& Boldyrev, A. I. Chemical bonding analysis of excited states using the Adaptive Natural Density Partitioning method. Phys. Chem. Chem. Phys. 21, 9590-9596 (2019).

42. Goicoechea, J. M. \& Sevov, S. C. Deltahedral germanium clusters: insertion of transition-metal atoms and addition of organometallic fragments. J. Am. Chem. Soc. 128, 4155-4161 (2006).

43. Frisch, M. J. et al. Gaussian 16, Revision B.01 (Gaussian, Inc., Wallingford, 2016).

44. Schäfer, A., Huber, C. \& Ahlrichs, R. Fully optimized contracted Gaussian basis sets of triple zeta valence quality for atoms Li to Kr. J. Chem. Phys. 100, 5829-5835 (1994)

45. Adamo, C. \& Barone, V. Toward reliable density functional methods without adjustable parameters: The PBE0 model. J. Chem. Phys. 110, 6158-6170 (1999).

46. Lu, T. \& Chen, F. Multiwfn: a multifunctional wavefunction analyzer. J. Comput. Chem. 33, 580-592 (2012).

47. Silvi, B. \& Savin, A. Classification of chemical bonds based on topological analysis of electron localization functions. Nature 371, 683-686 (1994).

48. Amsterdam Density Functional (ADF 2016) Code. http://www.scm.com (2020).

49. Wolff, S. K., Ziegler, T. V., Lenthe, E. \& Baerends, E. J. Density functional calculations of nuclear magnetic shieldings using the zeroth-order regular approximation (ZORA) for relativistic effects: ZORA nuclear magnetic resonance. J. Chem. Phys. 110, 7689-7698 (1999).

50. Sheldrick, G. M. SHELXT-Integrated space-group and crystal-structure determination. Acta Cryst. A. 71, 3-8 (2015).

51. Dolomanov, O. V., Bourhis, L. J., Gildea, R. J., Howard, J. A. K. \& Puschmann, H. OLEX2: a complete structure solution, refinement and analysis program. J. Appl. Crystallogr. 42, 339-341 (2009).

52. Spek, A. L. Structure validation in chemical crystallography. Acta Cryst. D. 65, 148-155 (2009).

53. Spek, A. L. PLATON SQUEEZE: a tool for the calculation of the disordered solvent contribution to the calculated structure factors. Acta Crystallogr. Sect. C Cryst. Struct. Commun. 71, 9-18 (2015).

\section{Acknowledgements}

This work was supported by the National Natural Science Foundation of China (21971118 and 21722106 to Z.M.S.). A.I.B. gratefully acknowledges support by the USA National Science Foundation (Grant CHE-1664379) and the support and resources from the Centre for High Performance Computing at the University of Utah. A.M.-C. acknowledges financial support from FONDECYT 1180683.

\section{Author contributions}

Z.M.S. conceived the project and designed the experiments. H.L.X. performed the synthesis. N.V.T., A.M.C., and A.I.B. performed the quantum chemical calculations and analyzed the data. Z.C.W., W.X.C., and L.Q. performed the single-crystal X-ray diffraction, energy dispersive X-ray spectroscopy and electrospray ionization mass spectrometry, and analyzed the data. All authors co-wrote the manuscript.

\section{Competing interests}

The authors declare no competing interests. 


\section{Additional information}

Supplementary information is available for this paper at https://doi.org/10.1038/s41467020-19079-Z.

Correspondence and requests for materials should be addressed to A.I.B. or Z.-M.S.

Peer review information Nature Communications thanks the anonymous reviewer(s) for their contribution to the peer review of this work.

Reprints and permission information is available at http://www.nature.com/reprints

Publisher's note Springer Nature remains neutral with regard to jurisdictional claims in published maps and institutional affiliations. (c) (i) Open Access This article is licensed under a Creative Commons Attribution 4.0 International License, which permits use, sharing, adaptation, distribution and reproduction in any medium or format, as long as you give appropriate credit to the original author(s) and the source, provide a link to the Creative Commons license, and indicate if changes were made. The images or other third party material in this article are included in the article's Creative Commons license, unless indicated otherwise in a credit line to the material. If material is not included in the article's Creative Commons license and your intended use is not permitted by statutory regulation or exceeds the permitted use, you will need to obtain permission directly from the copyright holder. To view a copy of this license, visit http://creativecommons.org/ licenses/by/4.0/.

(C) The Author(s) 2020 